\title{
International Groups Meet at Fall Meeting
}

\author{
European, Asian, and Australian Scientists Outline MRS-Style Activities for 1986
}

Three meetings conducted during the 1985 Fall Meeting brought the international research community and the Materials Research Society closer together in goals and plans for the coming year.

\section{Asia and Australia}

On Thursday afternoon the MRS Executive Committee met with colleagues from Asia and Australia to discuss recent activities. MRS President Elton Kaufmann stressed the Society's willingess to encourage and cooperate with Asian and Australian societies to promote the interdisciplinary approach to materials research activities.

Professor H. T. Li of Tsinghua University, Beijing, China reported that, with the endorsement of the Academy of Sciences, scientists in China were starting to form an MRS-type society. Likewise, the Australians also demonstrated enthusiasm for the MRS approach to technical meetings.

During the discussion preliminary plans for the 1988 International Conference on the Science and Technology of Materials were also formulated. The conference is tentatively scheduled for June 1988 in Tokyo.

\section{Europe}

During a meeting held Tuesday evening, representatives of the European Materials Research Society (E-MRS) reported on the two highly successful technical meetings they sponsored in 1985 at Strasbourg. The European Spring Meeting consisted of

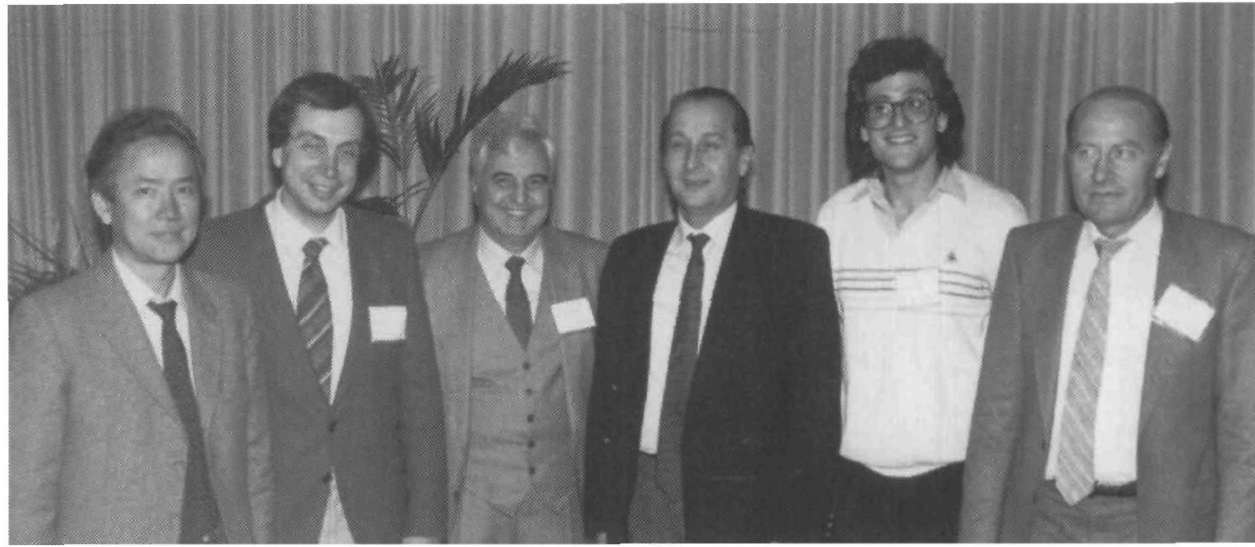

European-MRS representatives (left to right): V.T. Nguyen (CNET Grenoble), B. Stritzker (IFF/KFA), M. Balkanski (University of Pierre and Marie Curie), P. Siffert (Centre de Recherche Nucleaire), Y. Nissim (CNET), and G. Harbeke (RCA Laboratory).

three symposia: Energy Beam-Solid Interactions and Transient Thermal Processing (chaired by V.T. Nguyen and A. G. Cullis), Materials Under Extreme Conditions (chaired by $E$. Lusher, $H$. Ahlborn, and $H$. Fredriksson), and Semiconductor Quantum Well Structures and Superlattices (chaired by K. Ploog and N. T. Linh). The meeting was attended by 350 enthusiastic materials research scientists from both Europe and the United States.

The E-MRS Fall Meeting, held the last week in November, featured three symposia with the common theme of Advanced Materials Research and Development for

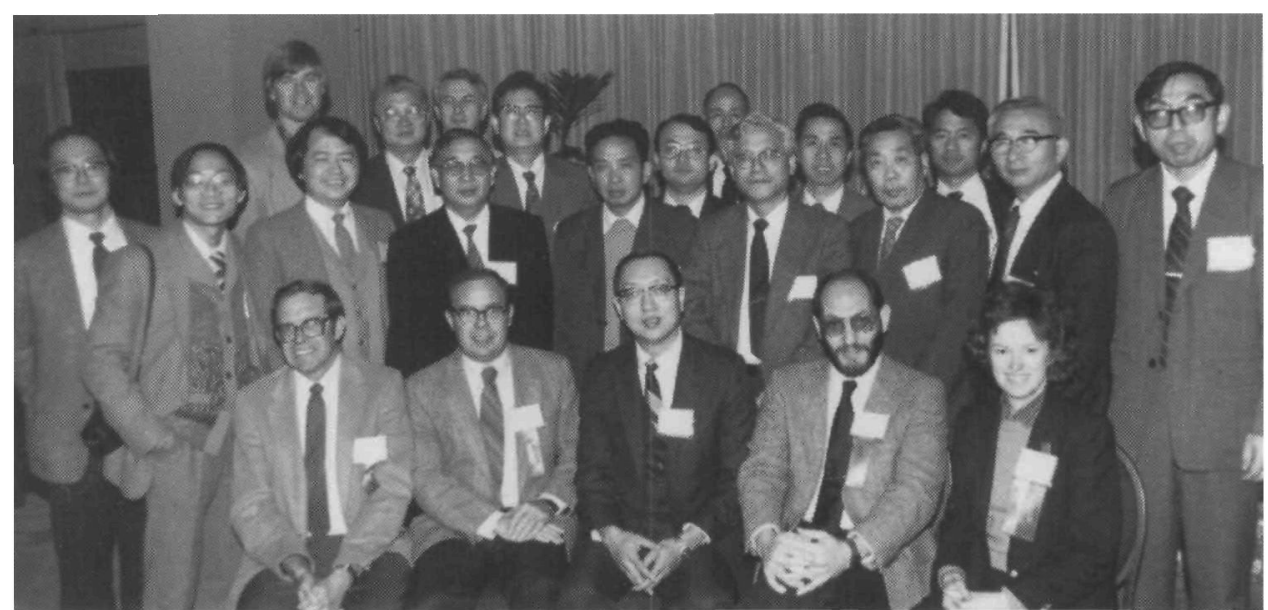

Materials scientists from Asia meet in Boston with MRS Officers. Bottom row (left to right): MRS Immediate Past President Woody White, President-Elect Gordon Pike, MRS Chairman-International Relations Bob Chang, MRS President Elton Kaufmann, MRS Second Vice President Kathy Taylor. Second row (left to right): H. Sasabe, Y-S. Chang, L.J. Chen, S.E. Hsu, S-C. Zou, S. Furukawa, H.D. Li, S. Somiya, D. Lin. Top row (left to right): MRS Treasurer Clif Draper, Y. Chen, MRS Executive Director John Ballance, $C$. Chen, M. Takai, T. Tokuyama, Y. Wang, T. Miyashita.
Transportation. This meeting had an attendance of 450 due to the excellent and timely topic selection. W. J. G. Bunk (Cologne, West Germany) and J. G. Wurm (Brussels, Belgium) chaired the overall meeting. The symposium on Light Metals was chaired by R. J. H. Wanhill (Noordoostpolder, The Netherlands), on Composites by P. Lamicq (St. Médard En Jalles, France), and on Ceramic Coatings for Heat Engines by I. Kuernes (Oslo, Norway).

A Spring Meeting is planned for June 1986 in Strasbourg (see related article in this issue). The organization is also planning its first summer school to be held in 1986. For the past several years, E-MRS has organized excellent, multidisciplinary technical meetings while operating simply as an unincorporated committee of scientists. Because of the success of their activities, the committee has begun the process of formally incorporating as a recognized European organization. During the 1985 Spring Meeting, a set of statutes governing E-MRS was drafted. Based on comments solicited from interested researchers, a final version has been produced. As secretary of the provisional committee, Paul Siffert has sent a copy of the statutes to committee members in Europe for their approval. The approved statutes will be registered with the French Court which will confer the incorporated status to E-MRS and thus permit them to be officially recognized as a scientific society by all countries of Europe.

Applications for membership in E-MRS are available from Paul Siffert, Centre de Recherches Nucleaires, Laboratoire PHASE, 67037 Strasbourg Cedex, France; telephone (88) 286543 . 